\title{
ボールミル粉砕によるポリビニルピロリドンの分子量低下*1)
}

\author{
金 庭 延 慶** 池川昭子**
}

\section{Degradation of Poly-Vinylpyrrolidone by Ball-Milling}

\author{
by \\ Nobuyoshi Kaneniwa and Akiko IkeKawa \\ (School of Pharmaceutical Sciences, Showa University, Tokyo)
}

Molecular weight of poly-vinylpyrrolidone decreased by ball-milling in nitrogen, air or oxygen. After 420 hours of ball-milling, polyvinylpyrrolidone of molecular weight $9.6 \times 10^{5}$ degraded to about $2 \times 10^{4}$. Equation (1) was applied to the relation between $-d M / d t$ and $M$.

$$
-d M / d t=K_{m} M^{\beta_{1}}\left\{1-\left(M_{t=\infty} / M\right)^{\beta_{2}}\right\}
$$

Numerical values of $K_{m}, \beta_{1}$ and $\beta_{2}$ for the case of ball-milling in oxygen were the largest and those for the case of nitrogen were the smallest. Gel filtration of the sample suggested much probability in the way that, in nitrogen, the segment of the molecular weight below $10^{5}$ was broken in order from the end of the polymer.

Investigation of elemental analysis, Nestler's reaction and decomposition point of the sample showed partial change in chemical structure caused by ball-milling. Partial change in solid constitution caused by ball-milling was also suggested by the measurement of glass temperature.

Equation (2) was applied to the first 150 hours of ball-milling, where $S$ is the surface area of the sample.

$$
d S / d t=k_{1} \cdot \exp \left(-k_{2} \cdot S\right)
$$

Parameter $k_{1}$ was large for the case of ball-milling in an oxygen-containing atmosphere, similar to that of $K_{m}$ in Equation (1).

(Received Feb. 25, 1971)

\section{1 緒言}

最近，プラスチックの粉砕は熱可塑性プラスチック の化粧，耐蝕を目的とした金属表面へのライニング, 粉末成型, プラスチックの再生などのために各分野か ら要求されている。一方, 製剂分野に沶いては低重合 度で分布の均一な水溶性高分子が必要である。

粉砕などの機械的処理は有機物にメカノケミカル効 果を与えることが報告されている. 番匠らは銅フタ口 シアニンは摩砕によって低温安定の $\beta$ 型から高温安定 $の \alpha$ 型汇転移することを見い出し, Kargin らは窒素 ふん囲気中でのボールミル処理によりポリマーの分子 量が低下することを報告している。これらの現象をよ り深く検討し機械化学反応の機構を明らかにすること は，上記のことから重要と思われる。

今回は, 解毒剂, 結合剂, 増粘剂, 血漿増量剂など に用いられ薬学的に重要な高分子であるポリビニルピ ロリドンのボールミル粉哗による分子量低下について 検討した。

$$
2 \text { 実 験 方 法 }
$$

* 原稿受理 昭和 46 年 2 月 25 日

** 昭和大学薬学部 東京都品川区旗の台
試料としては和光純薬工業株式会社製のポリビニル ピロリドン K90 (PVP K90), PVP K30 拈よび東京 化成工業株式会社製の PVP K15 を使用した。

内径 $10 \mathrm{~cm}$, 内容量 $870 \mathrm{ml}$ のステンレス製チュー ブミルに比重 8.15 , 直径 $2.5 \mathrm{~cm}$ のステンレス製ボー ル 5 個, $1.9 \mathrm{~cm}$ のボール15個扣よび試料粉末 $20 \mathrm{~g}$ 插入し, 99 r.p.m の速さでミルを回転した。窒素お よび酸素中での紛砕にはミルのフタの部分を改良して 用いた。

各時間ごとに約 $100 \mathrm{mg}$ の試料を取り出し, 水溶液

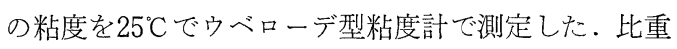
は東芝ベックマン社製 930 型空気比較式比重計で絰素 中で測定し, 表面積は空気透過法によって求めた。分 子量分布はファルマシア社製 $\mathrm{K} 25 / 45$ タイプのセファ デックスカラムを用いて, $22 \mathrm{mg} / \mathrm{ml}$ の試料水溶液 1 $\mathrm{ml}$ をセファローズ $6 \mathrm{~B}$ によって蒸留水で上昇法て分 画した。水溶液の濃度は $215 \mathrm{~m} \mu$ の吸光度を日立 139 型分光光度計で測定して求めた. 分解点の測定には柳 本製作所の微量融点測定装置を用いた，試料の温度を $6^{\circ} \mathrm{C} / \mathrm{min}$ の速度で上昇させ, 試料がかすかに黄変し はしめた点を分解点とした。ガラス転移点は膨張計法 
により，温度上昇速度は $2^{\circ} \mathrm{C} / \mathrm{min}$ とした。

\section{3 実験結果および考察}

\section{$3 \cdot 1$ 分子量低下}

Fig. 1 亿示すように, 試料水溶液の固有粘度〔 $\eta 〕$, は 粉砕時間とともに徐々に低下した。(1)式を用いて分子 量, $M$ を求めると, 平均分子量 $9.6 \times 10^{5}$ の試料は 420 時間粉砕することによって約 $2 \times 10^{4}$ に低下した。 $[\eta]-t$ 曲線の各点に拈ける切線のこ5配, $d[\eta] / d t$, を

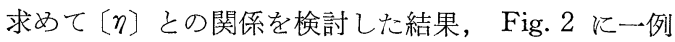
を示すように，(2)式が適用できることがわかった。

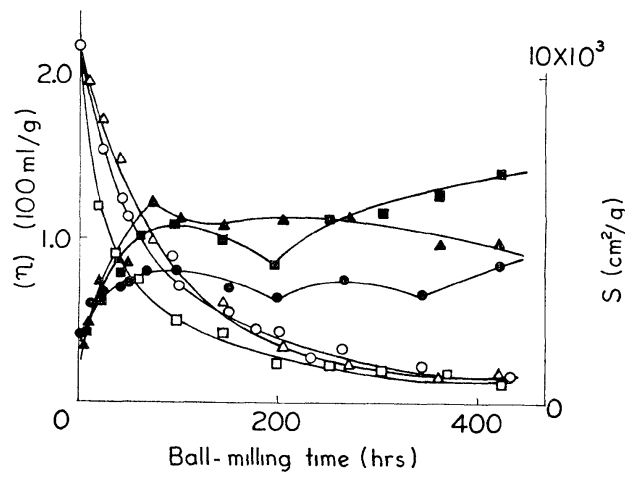

$\begin{array}{lll}\text { Atmosphere } & (\eta) & S \\ \text { Nitrogen } & \Delta & \Delta \\ \text { Air } & 0 & \\ \text { Oxygen } & \square & \end{array}$

Fig. 1. Influence of ball-milling on surface area and intrinsic viscosity of aqueous solution of poly-vinylpyrrolidone powder.

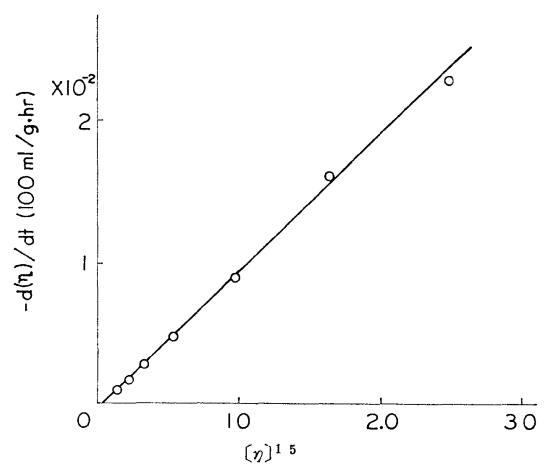

Fig. 2 Rate of decrease of intrinsic viscosity of the aqueous solution by ball-milling polyvinylpyrrolidone powders in air.

$$
\begin{gathered}
{[\eta]=K \cdot M^{\alpha}} \\
K=1.9 \times 10^{-4}, \quad \alpha=0.68 \\
-d[\eta] / d t=k\left([\eta]^{n}-[\eta]_{t=\infty}^{n}\right)
\end{gathered}
$$

$k, n$ ：ふ九用気に依存するパラメータ $[\eta]_{t=\infty}$ ：無限時間粉砕した場合の試料 $[\eta]$ の各ふん囲気中での $k, n,[\eta]_{t=\infty}$ の值を Table I に示

\begin{tabular}{|c|c|c|c|c|c|c|}
\hline Atmosphere & $k\left(h \mathrm{r}^{-1}\right)$ & $n$ & $\left(\begin{array}{c}\left(100 \eta_{t}=\infty\right. \\
\mathrm{ml} / \mathrm{g})\end{array}\right.$ & $K_{n}\left(h^{-1}\right)$ & $\beta_{1}$ & $\beta_{2}$ \\
\hline Nitrogen & $48 \times 10^{-3}$ & 1 & 014 & $71 \times 10^{-3}$ & 1 & 068 \\
\hline Alr & $93 \times 10^{-3}$ & 15 & 014 & $51 \times 10^{-3}$ & 13 & 10 \\
\hline Oxygen & $88 \times 10^{-3}$ & 2 & 014 & $18 \times 10^{-3}$ & 17 & 18 \\
\hline
\end{tabular}

Table I. Numerical values of paramers in Equation (2) and (4).

す.(1)，(2)式から(3)式が得られる。

$$
\begin{gathered}
\quad-\frac{d M}{d t}=K_{m} \cdot M^{\beta_{1}}\left\{1-\left(\frac{M_{t=\infty}}{M}\right)^{\beta_{2}}\right\} \\
K_{m}=(k / \alpha) \cdot K^{n-1}, \beta_{1}=(n-1) \alpha+1, \quad \beta_{2}=n \alpha
\end{gathered}
$$

(2)，(3)式はこれ以下には低下し得ない限界分子量, $M_{t=\infty}$, の存在することを示しており，分子量 $M$ の分 子は $N=\left(M / M_{t=\infty}\right)-1$ の切断点を持つことになる. $M \gg M_{t=\infty}$ の時，(3)式は(4)式であらわされる.

$$
\begin{gathered}
-d N / d t=K_{n} \cdot N^{\beta_{1}}\left(1-1 / N^{\beta^{2}}\right) \\
K_{n}=K_{m} \cdot M_{t=\infty}^{(n-1) \alpha}
\end{gathered}
$$

Baramboim は数種の有機高分子を窒素および大気 中でボールミル処理し, 分子量の低下速度は切断点の 数に比例することを見い出したが，これは(3)，(4)式で $n=\alpha=1$ の場合汇相当する.

ミルが一回転することによってすべてのボールがー 番高いところなで持上げられ試料に衝撃を与える，ま た主鎖の C-C 結合の切断には C-C結合エネルギに相当 する $83 \cdot 1 \mathrm{kcal} / \mathrm{mole}$ が必要であるという二つの仮 定のもとに，(4)式を用いてボールミル粉砕初期の分子 鎖切断エネルギ効率を算出すると, 窒素中では 1.0 , 空気中では $1.3 \times 10^{4}$, 酸素中では $1.1 \times 10^{13}$ という異 常に大きな值が得られた。この結果からC-C結合切断 に必要なエネルギはC-C結合エネルギよりはるかに小 さく，また酸素は分子鎖切断エネルギの低下に関与し ていると思われる。 Butyagin らはポリエチレンおよ びポリプロピレンを不活性ガス中で粉砕することによ ってフリーラシカルが生成することを ESR によって 確認した。ささらにポリスチレンなどのポリマーを酸素 の存在下で粉砕すると発光し, 粉砕をやめても 10～15 分間継続したが，真空中や不活性気体中ではこのよ5 な現象はみられなかったと報告している。ポリビニル ピロリトンンの場合にも分子鎖切断にラシカルが関与し て扣り，酸素はラシカルの安定性に影響しているとも 思われる。

(2)（4)式によれば， $M_{t=\infty}$ (Table I と(1)式から1.6 $\left.\times 10^{4}\right)$ 以下の分子量の試料はボールミル粉砕によっ て分子量は低下しないはずである。 PVP K15（平均 分子量 $7.5 \times 10^{3}$ ) を窒素中で150時間あるいは酸素中 で 200 時間粉砕しても，固有粘度の低下も分子量分布 の変化もみとめられなかった。

窒素ふん囲気中での PVP K90 のボールミル 粉砕 


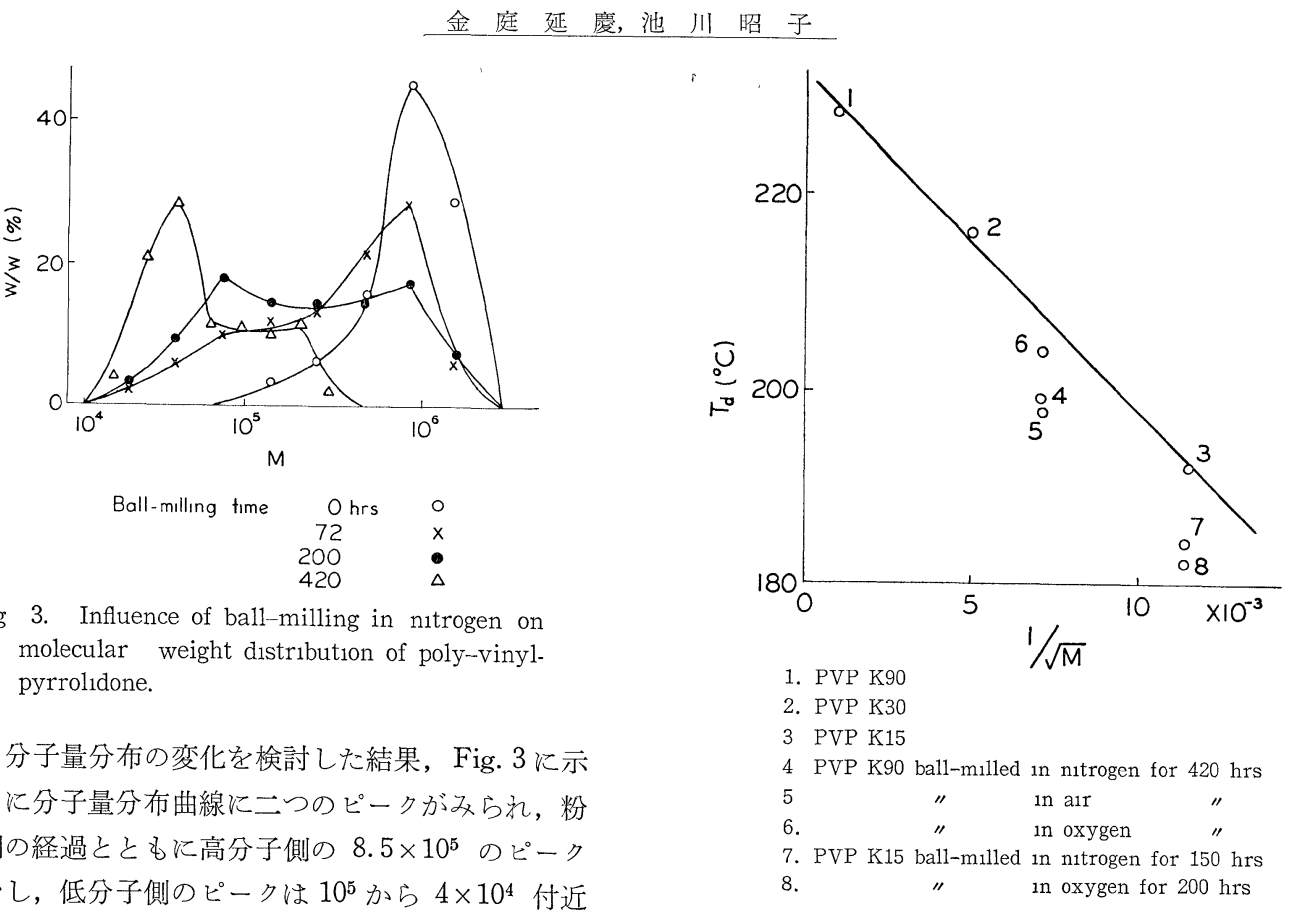

による分子量分布の変化を検討した結果, Fig. 3 亿示 すように分子量分布曲線に二つのピークがみられ，粉 砕時間の経過とともに高分子側の $8.5 \times 10^{5}$ のピーク は減少し, 低分子側のピークは $10^{5}$ から $4 \times 10^{4}$ 付近 ヘシフトしながら増大した。この事実は $8.5 \times 10^{5}$ 程

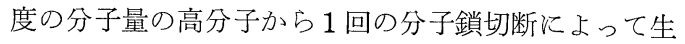
成した分子は $10^{5}$ 以下の分子量のるのが大部分である ことを暗示している。窒素中では $10^{5}$ 以下の分子量の るのがはじから切断される確率が高いと考克られる。

\section{$3 \cdot 2$ 化学構造および固体構造の変化}

Table II は PVP K90, PVP K15 おょよ゙これらを 粉砕した試料の元素分析值を示している.PVP K 90 を酸素中で粉砕した場合と PVP K15を粉粋した場合 には窒素含量がごくわずか減少した。これらの試料で、 はネスラー反応によりアンモニアが検出されたが, 他 の試料では検出できなかった。限界分子量以上の試料 を酸素中で粉碎する場合とそれ以下の試料を粉砕する 場合には側鎖の $C-N$ 結合が切断されるるのと思われ る。

粉砕しないもとの試料では, 分解点, $T_{d}$, 之分子量 との間にはFig. 4 亿示すよらな関係が得られた. PVP K15 の分解点は粉确によって低下し，PVP K90を粉

Table II. Results of elemental analysis.

\begin{tabular}{l|l|r|l|l|l|l}
\hline Sample & Atmosphere & $\begin{array}{c}\text { Ball- } \\
\text { milling- } \\
\text { t1me }\end{array}$ & $C$ & $H$ & $N$ & $\begin{array}{l}\text { Nestler } \\
\text { reaction }\end{array}$ \\
\hline PVP K90 & & $\begin{array}{r}\text { hrs } \\
0\end{array}$ & 6248 & 828 & 1197 & - \\
PVP K90 & Nitrogen & 420 & 6118 & 8.12 & 1175 & - \\
PVP K90 & A1r & 420 & 6196 & 823 & 1192 & - \\
PVP K90 & Oxygen & 420 & 6053 & 801 & 11.49 & + \\
PVP K15 & & 0 & 6137 & 830 & 1219 & \pm \\
PVP K15 & Nitrogen & 150 & 6100 & 819 & 1174 & + \\
PVP K15 & Oxygen & 200 & 6103 & 8.18 & 11.80 & + \\
\hline
\end{tabular}

Fig 4 Influence of ball-milling on decomposition point of poly-vinylpyrrolidone.

碎した試料の分解点も $T_{d}-1 / \sqrt{\mu}$ 直線より低かった。 IR, UV, NMR でははっきりして影響はみとめられ なかったがボールミル粉砕によって微細な化学構造 の変化が生じたものと思われる.

Fig. 5 亿示すように, PVP K15 のガラス転移点, T はホホールミル粉砕によって低下した。 PVP K90, PVP K15 および PVP K90 を㗧素中で粉碎した試料 の場合には, $T_{g}$ 之 $1 / M$ との間值線関係がみられ 先. PVP K30 の $T_{g}$ は $T_{g}-1 / M$ 直線より低かった が, PVP K30 の密度 (1.008) は PVP K90, PVP K15 の密度（それぞれ 1.338 抢よび 1.214）に比べて 低いためと思われる，PVP K90 を空気岗るいは酸素 中で粉砕した試料の $T_{g}$ は $T_{g}-1 / M$ 直線より低かっ た。限界分子量以上の試料を酸素の存在下で粉砕する

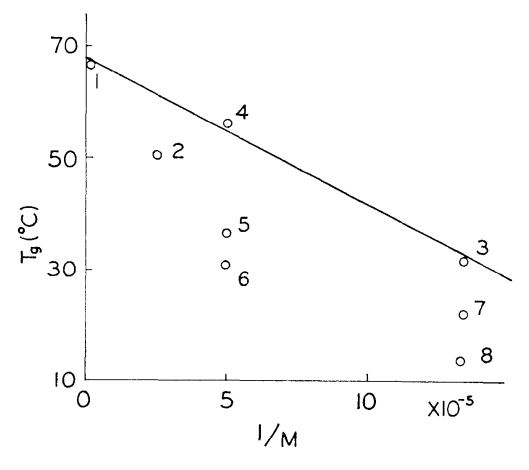

Numbering : See Fig 4

Fig. 5. Influence of ball-milling on glass temperature of poly-vinylpyrrolidone. 
場合と限界分子量以下の試料を粉砕する場合には固体 の微細構造が変化して, 凝集エネルギ密度が低下する のではないかと考觉られる。皇こで粉末X線法でこの 点を検討したが，はっきりした影響はみとめられなか った。

\section{$3 \cdot 3$ 表面積}

Fig. 1 亿示すよ5に, PVP K90 の表面積は粉硡時 間の経過とともに增大し,100時間後には注ぼ一定とな ったが, 酸素中では 200 時間後に再び増大しはじめた。 PVP K15 の粉砝によって得られた表面積の最大值, $1.34 \times 10^{4} \mathrm{~cm}^{2} / \mathrm{g}$ ，は PVP K90 の150時間粉砕による 表面積の值よりはるかと大きかった。表面積 $S$ と〔 $\eta 〕$ との関係を検討すると，Fig. 6 亿示すょうに，窒素㟧

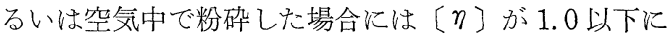
なるとSは添汸一定となったが，酸素中で紛砕した場

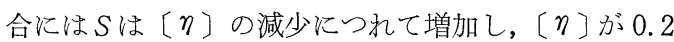
以下になるとその傾向は著しくなった。これらの現象 は, 酸素中での粉砕によって側鎖の $C-N$ 結合が切断

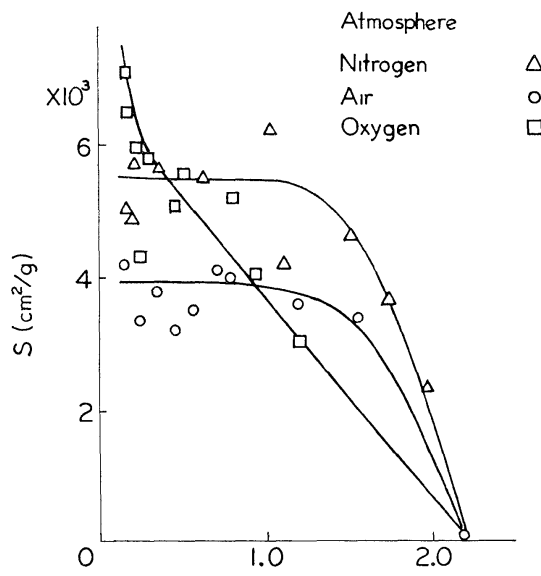

[n] $(100 \mathrm{~m} 1 / \mathrm{g})$

F1g. 6 Relation between surface area and intrinsic viscosity of aqueous solution of ball-milled samples of poly-vinylpyrrolidone powders.

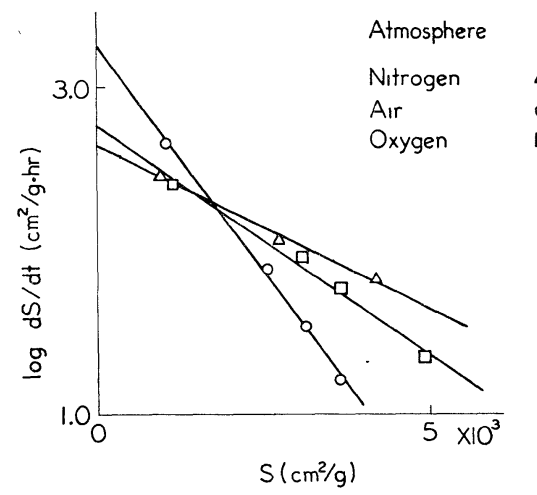

Fig. 7. Rate of increase of surface area of polyvinylpyrrolidone by ball-milling.
され，試料表面の物理化学的性質が变化したためと思 われる。

150 時間までの粉砕に対しては, Fig. 7 に示すよろ そ（5)式が適用できた。

$$
d S / d t=k_{1} \exp \left(-k_{2} S\right)
$$

パラメータ $k_{1}$ は粒子の大きさが $S$ 零と近似できる程 度に大きい場合の表面積増大速度と考兄られるが，酸 素の存在する場合に大きく，(2)式の $k$ 之類似の傾向が みられた。长は窒素中で最小，空気中で最大となり， 粉砕によって得られた表面積の最大值と逆の傾向が得 られた。 $k_{2}$ は表面積增大による試料の付着凝集性の增 加の $d S / d t$ 亿対する影響を示していると思わ机る。空 気中での粉研の場合 $k_{1}, k_{2}$ は著しく大きかったが, これは水分の影響であるう， $d S / d t$ は $k_{1}$ が大きく $k_{2}$ が小さい場合に大さく, 従って $\left(\log k_{1}\right) / k_{2}$ 之相関性 があると考光られる。 $k_{1}, k_{2},\left(\log k_{1}\right) / k_{2}$ の值は Table III 飞ま之めてある。

Table III. Numerical values of $k_{1}, k_{2}$ and $\left(\log k_{1}\right) / k_{2}$.

\begin{tabular}{l|c|c|c}
\hline Atmosphere & $k_{1}\left(\mathrm{~cm}^{2} / \mathrm{g} \mathrm{hr}\right)$ & $k_{2}\left(\mathrm{~g} / \mathrm{cm}^{2}\right)$ & $\left(\log k_{1}\right) / k_{2}$ \\
Nitrogen & $045 \times 10^{3}$ & $047 \times 10^{-3}$ & $13 \times 10^{4}$ \\
A1r & 16 & 123 & 060 \\
Oxygen & 053 & 086 & 073 \\
\hline
\end{tabular}

（昭和45年11月18日 第 8 回粉体に関する討論会にて講演）

\section{参考 文 献}

1）金庭延慶，池川昭子，薬剂学投稿中，

2) 高橋 浩, 堤 和男, 化学増刊 31 , “粉体の物性と工学”, p 55 (1967).

3) 番匠吉衛, 鈴木 茂, 斉藤イホ, 関口辰夫, 工業化学雑 誌, 67, 168 (1964).

4) Baramborm, N K., Zh F1z. Kh1m., 32, 432 (1958); Dok1 Akad Nauk SSSR, 114, 568 (1957).

5) Kargin, B K., and G.E. Betts, Rub. Chem. Techn., 29, 485 (1956).

6）水渡英二, 荒川正文, 高橋 允, 工業化学雑誌, 59, 307 (1956).

7) 植松市太郎, 実験化学講座, 8, 83 (1966).

8) Frank, H, and G. Levy, J. Polymer Sci, 10, 371(1953).

9）島内武彦, “構造化学講義資料”, p 85 (1965) 裳華房

10) Radtsig, V. A, and P. Yu. Butyagin, Vysokomol. Soedim Ser A9 (12) 2549 (1967).

11) Kislyuk, M U, and P. Yu. Butyagim, $\imath b \imath d$., Ser. B9 (8) 612 (1967).

12) Fox, T. G, Jr., and P. J Flory, J. App. Phys., 21, 581 (1950).

13) Boyer, R.F., J Appl. Phys., 25, 825 (1954); 植松 市太郎，植松俶子，高分子化学， 17，222 (1960); 河合 鱗次郎, 高分子, 6, 348 (1957).

14）他川昭子，今川歓二，大森利枝，金庭延慶，Chem. Pharm. Bull., 投稿中. 